Supporting Information

\title{
Graphene oxide promoted cadmium uptake by rice in soil
}

Yijia He ${ }^{1}$, Lichao Qian ${ }^{2}$, Ke Zhou $^{3}$, Ruirui Hu ${ }^{l}$, Meirong Huang ${ }^{1}$, Min Wang ${ }^{l}$, Guoke Zhao ${ }^{1}$,

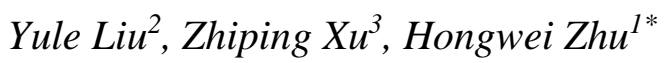

${ }^{1}$ State Key Lab of New Ceramics and Fine Processing, School of Materials Science and

Engineering, Tsinghua University, Beijing 100084, China

${ }^{2}$ Center for Plant Biology and MOE Key Laboratory of Bioinformatics, School of Life

Sciences, Tsinghua University, Beijing 100084, China

${ }^{3}$ Applied Mechanics Laboratory, Department of Engineering Mechanics, Tsinghua University, Beijing 100084, China

*Corresponding author. Email: hongweizhu@tsinghua.edu.cn 
Table S1. 12-6 Lennard-Jones potential parameters and atomic charges used in the OPLS for graphene, carboxylate groups on graphene edges, and the $\mathrm{Cd}(\mathrm{II})$ ion. $\mathrm{C}_{0}, \mathrm{C}_{1}$ and $\mathrm{C}_{2}$ denote carbon atoms in the $s p^{2}$ region of graphene, the carboxylate group, and the atom bonded to $\mathrm{C}_{1}$.

\begin{tabular}{|c|c|c|c|c|c|}
\hline & Atomic site & $\varepsilon(\mathrm{kcal} / \mathrm{mol})$ & $\sigma(\mathrm{nm})$ & $q(e)$ & Bond length (nm) \\
\hline Graphene & $\mathrm{C}_{0}$ & 0.068 & 0.34 & 0 & $l_{\mathrm{C}-\mathrm{C}}=0.142$ \\
\hline \multirow{3}{*}{ Carboxylate } & $\mathrm{C}_{1}\left(\right.$ in $\left.\mathrm{COO}^{-}\right)$ & 0.105 & 0.375 & 0.7 & \multirow{3}{*}{$\begin{array}{c}l_{\mathrm{C} 1-\mathrm{O}}=0.125 \\
l_{\mathrm{C} 1-\mathrm{C} 2}=0.1522\end{array}$} \\
\hline & $\mathrm{O}$ & 0.21 & 0.296 & -0.8 & \\
\hline & $\mathrm{C}_{2}$ (in graphene) & 0.068 & 0.34 & -0.1 & \\
\hline \multirow{2}{*}{ Water } & $\mathrm{H}$ & 0 & 0 & 0.4236 & \multirow{2}{*}{$l_{\mathrm{O}-\mathrm{H}}=0.1$} \\
\hline & $\mathrm{O}$ & 0.155 & 0.317 & -0.8472 & \\
\hline $\mathrm{Cd}(\mathrm{II})$ & $\mathrm{Cd}$ & 0.00848 & 0.2394 & +2 & l \\
\hline
\end{tabular}




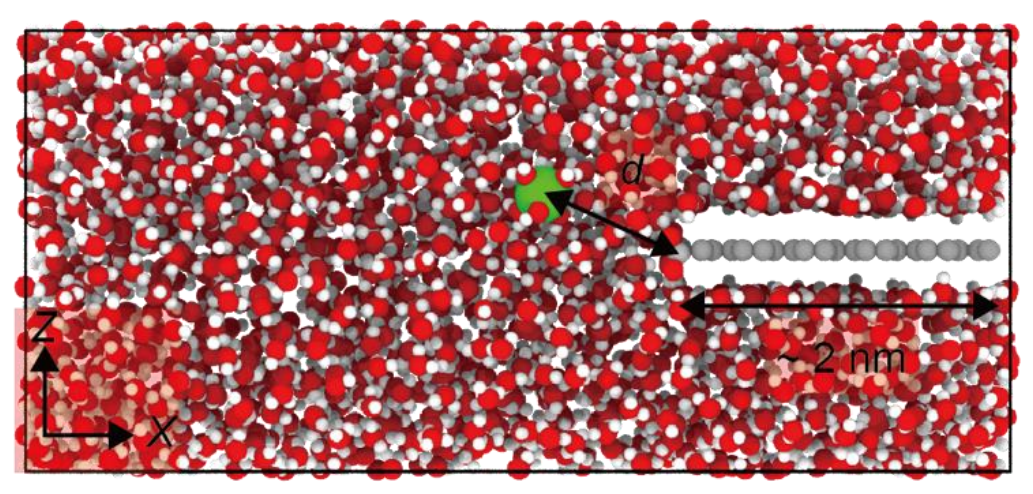

Figure S1. The MD simulation model. 

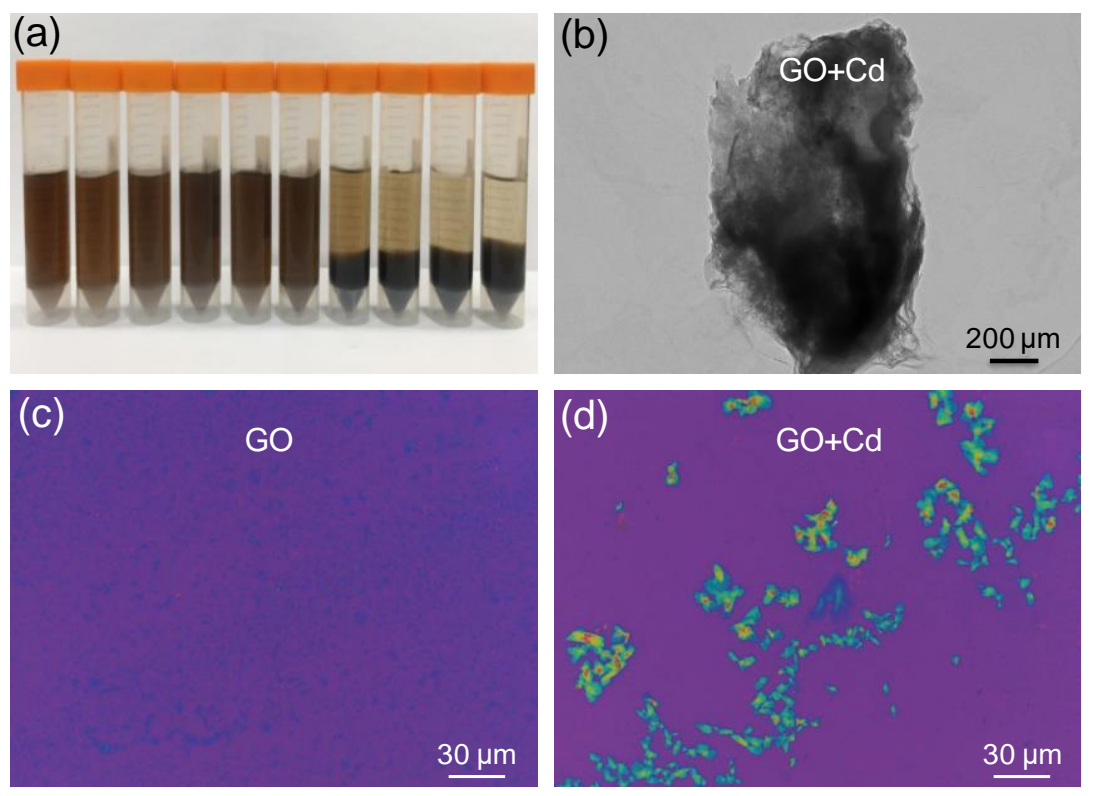

Figure S2. (a) Bulk aggregations of GO in solutions with varied initial Cd(II) concentration $(5,10,15,20,25,30,35,40,45$ and $50 \mathrm{mg} / \mathrm{L})$. (b) TEM image of aggregated GO in the solution (initial $\mathrm{Cd}(\mathrm{II})$ concentration: $50 \mathrm{mg} / \mathrm{L}$ ). (c, d) Optical images of GO and aggregated GO in the solution (initial Cd(II) concentration: $50 \mathrm{mg} / \mathrm{L}$ ). 
(a)

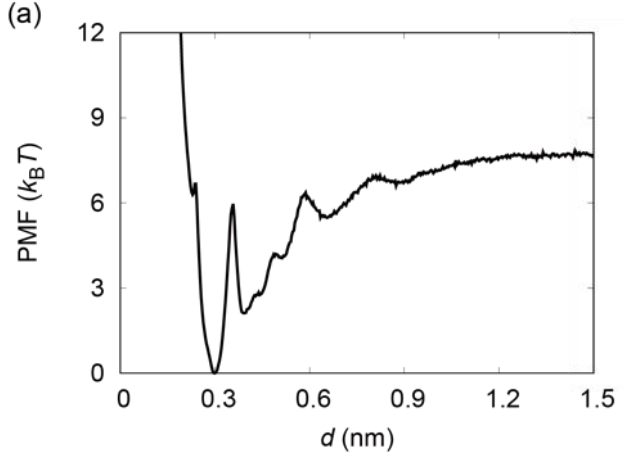

(c)

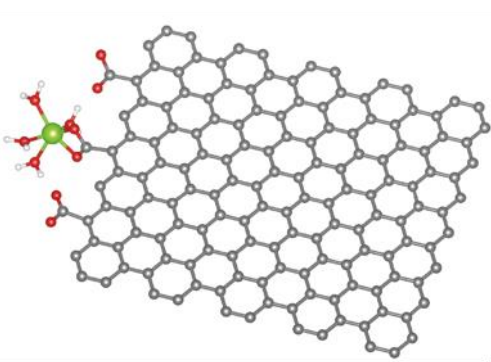

(b)

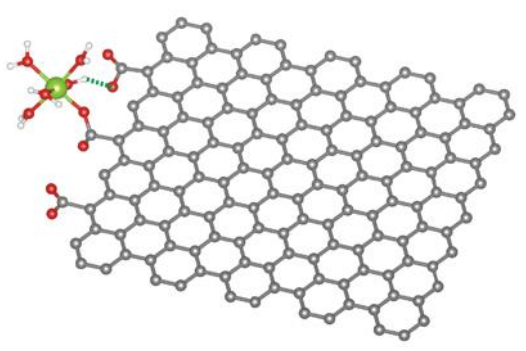

(d)

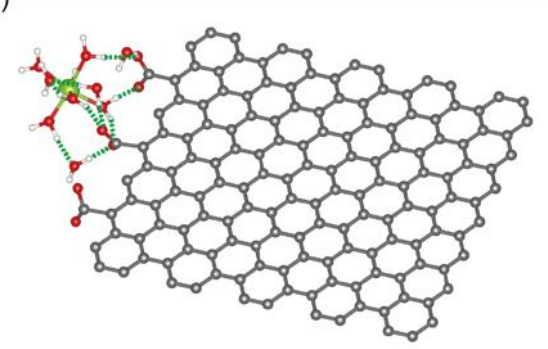

Figure S3. (a) PMF calculated from MD simulations. (b-d) Atomic structures illustrating absorption of hydrated $\mathrm{Cd}(\mathrm{II})$ at carboxylate groups, which occurs while the ion is trapped at (b) single or (c) double $\mathrm{O}$ atoms of carboxylate groups, or (d) mediated by H-bonds (the green dash lines) between water molecules on the 1HS of ions and the oxygen-containing groups. The atoms in water are shown in red $(\mathrm{O})$ and white $(\mathrm{H})$ surrounding the $\mathrm{Cd}(\mathrm{II})$ ions (green). The interaction between the water molecules in the 1HS and the ion is indicated by solid lines. 

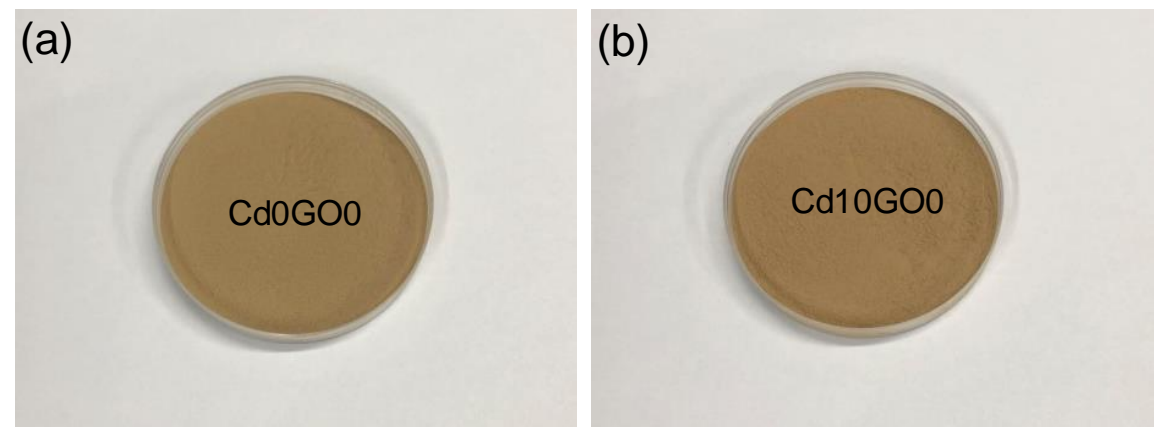

(c)

(d)
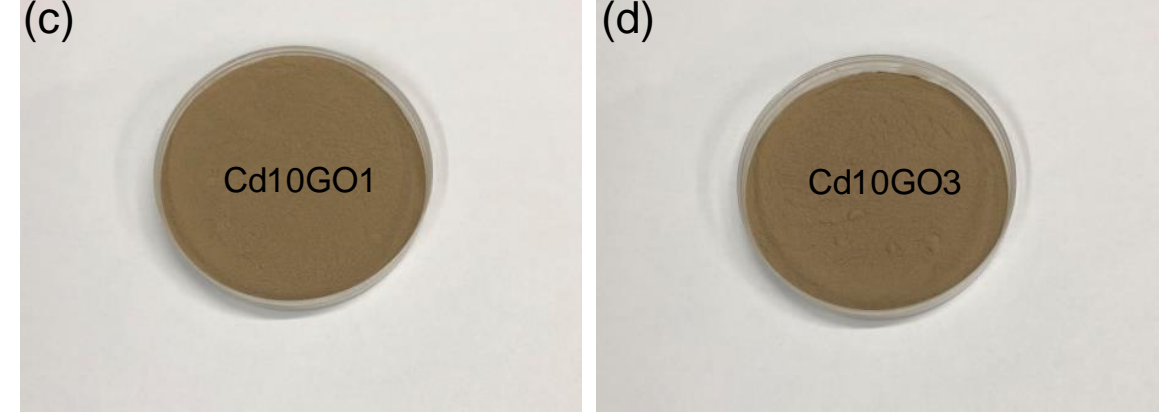

Figure S4. Photographs of soils treated with GO of different concentrations. 